\title{
Impact of ozone depletion on phytoplankton growth in the Southern Ocean: large-scale spatial and temporal variability
}

\author{
Kevin R. Arrigo \\ Oceans and Ice Branch, Code 971, NASA/Goddard Space Flight Center, Greenbelt, Maryland 20771, USA
}

\begin{abstract}
A numerical model has been used to assess the impact of decreased $\mathrm{O}_{3}$ concentrations over the Southern Ocean on phytoplankton production. The model includes components describing (1) atmospheric spectral radiation (280 to $700 \mathrm{~nm}$ ) as a function of time and latitude, (2) in-water biooptics, and (3) primary production, as determined by the depth-dependent spectral distribution of ambient irradiance and the action spectrum for photosynthesis. Model results show that in early spring, a $50 \%$ reduction in stratospheric $\mathrm{O}_{3}$ enhanced the integrated production within the euphotic zone by $\sim 9 \%$ at $75^{\circ} \mathrm{S}$ and by $0.5 \%$ at $50^{\circ} \mathrm{S}$, due to the increased transmission of photosynthetically usable radiation, PUR (400 to $700 \mathrm{~nm}$ ). Later, as solar zenith angles decreased, UV inhibition overcame PURinduced enhancement, and integrated phytoplankton production was inhibited, but by less than $1.0 \%$. A similar pattern resulted when observed $\mathrm{O}_{3}$ concentrations were used as model input, although the PUR-induced enhancement effect was substantially reduced. UV inhibition at normal $\mathrm{O}_{3}$ concentrations was most severe at the sea surface and dominated by UVA, reducing production by a maximum of $54 \%$. Simulating a $50 \%$ decrease in $\mathrm{O}_{3}$ concentration reduced production at the sea surface by at most an additional $13 \%$. However, integrating the effect throughout the light cycle and down to the base of the euphotic zone reduced the computed deleterious effect of added UVB to $<1.0 \%$. Because sea ice extent is greatest when and where $\mathrm{O}_{3}$ is at its minimum, and major phytoplankton blooms generally occur well after ozone concentrations have rebounded to normal levels, the potential impact of increased UVB transmission in the Southern Ocean is further reduced. It is concluded that increased transmission of UVB beneath the ozone hole would result in only a slight incremental increase in UV inhibition of depth-integrated phytoplankton production over that which occurs naturally.
\end{abstract}

KEY WORDS: Antarctica P Primary production - Ozone $\cdot$ UV inhibition

\section{INTRODUCTION}

The anthropogenic release of volatile compounds such as chlorofluorocarbons and bromine halons has led to a steady decrease in the concentration of stratospheric ozone $\left(\mathrm{O}_{3}\right)$ for more than a decade (Anderson et al. 1991). This $O_{3}$ loss is most pronounced over the Antarctic continent, where the depleted region is referred to as the ozone hole. Total column $\mathrm{O}_{3}$ concentrations (denoted $\left[\mathrm{O}_{3}\right]$ ) in the austral spring are often reduced to $<50 \%$ of their normal level of 344 Dobson units (DU) (Smith et al. 1992a) and result in increased transmission of ultraviolet radiation (UV), particularly UVB (280 to $320 \mathrm{~nm}$ ), into the upper layers of the ocean. UVA (320 to $400 \mathrm{~nm}$ ) is unaffected by changes in $\left[\mathrm{O}_{3}\right]$ because absorption is negligible in this range. The position and size of the Antarctic $\mathrm{O}_{3}$ hole varies dramatically throughout the year, reaching its maximum size during the early austral spring, coinciding with the initiation of major spring microalgal blooms.

Laboratory studies suggest that small doses of UVB can be extremely harmful to some species of antarctic microalgae (Karentz et al. 1991). Due to the concern over decreased stratospheric $\left[\mathrm{O}_{3}\right]$, and hence increased transmission of harmful UVB radiation, a number of recent investigations assessed the effect of UV radiation on phytoplankton production in the Southern Ocean. Helbling et al. (1992) measured photosynthetic 
rates on-deck using various broad band cut-off filters and demonstrated that at normal $\left[\mathrm{O}_{3}\right]$, UVA is responsible for $>50 \%$ of total UV inhibition of phytoplankton growth. Using a similar light filtering approach, but incubating their samples in situ, Holm-Hansen et al. (1993) showed that inhibiting levels of UVB reach to a depth of $20 \mathrm{~m}$. The first measurements of photosynthetic rates inside and outside the influence of an $\mathrm{O}_{3}$ hole were made by Smith et al. (1992a), who showed that $\mathrm{O}_{3}$ depletion does indeed result in reduced primary production rates. In contrast to the above studies which utilized broad band UV filters, Cullen et al. (1992) determined the UV action spectra for antarctic phytoplankton at much higher spectral resolution. This study showed that algae are extremely sensitive to short wavelength UVB radiation but that this sensitivity drops rapidly at longer wavelengths.

Investigations such as these have furthered our understanding of the respective roles of UVA and UVB in controlling phytoplankton production, and provided the foundation from which the influence of decreased $\left[\mathrm{O}_{3}\right]$ can be studied on much larger temporal and spatial scales. To do so requires a different strategy, however, one that is not restricted by the logistics of a field program, namely numerical simulation. The impact of reduced $\left[\mathrm{O}_{3}\right]$ on the spectral distribution of transmitted UVB is complex, varying greatly with time of day, date, and latitude. Because of the large size and longevity of the Antarctic $\mathrm{O}_{3}$ hole, a field program capable of determining this entire range of variation would be logistically impossible and prohibitively expensive. However, studying the effects of temporal changes in $\left[\mathrm{O}_{3}\right]$ over large spatial scales is relatively straightforward with numerical techniques. In fact, this approach has only recently become feasible due to (1) the development of accurate, high resolution radiative transfer models, which can calculate the spectral distribution of atmospheric UV radiation as a function of $\left[\mathrm{O}_{3}\right]$ and solar zenith angle, and (2) the determination of an accurate and detailed action spectrum for photosynthetic inhibition by UV. As additional data become available, this modeling approach will improve, allowing the inclusion of more phytoplankton taxa.

The impact of $\mathrm{O}_{3}$ depletion on the transmission of photosynthetically usable radiation (PUR, 400 to $700 \mathrm{~nm}$ ), a derivative of PAR (Morel 1978), and how this might influence phytoplankton production, has largely been ignored. $\mathrm{O}_{3}$ absorbs some radiation between 400 and $700 \mathrm{~nm}$, although extinction coefficients in this range are small compared to those between 280 and $320 \mathrm{~nm}$. However, at high latitudes, large zenith angles magnify absorption at all wavelengths by increasing the effective radiation pathlength through the atmosphere (Gregg \& Carder 1990). For example, a beam of light at a solar zenith angle of $80^{\circ}$ has a relative path-length approximately twice that of a $70^{\circ}$ beam. Diminishing $\left[\mathrm{O}_{3}\right]$ would increase the transmission of PUR over the Southern Ocean in the early spring when zenith angles are large and light is most limiting to algal production. Consequently, the effect of $\mathrm{O}_{3}$ depletion on radiation reaching the sea surface depends on the time of year, with an increase in the transmission of PUR early in the spring, and of UVB later, as zenith angles increase. In the present paper, a bio-optical model of phytoplankton production has been coupled to a detailed radiative transfer model and used to assess the effect of decreased column $\mathrm{O}_{3}$ on PUR and UVB radiation and how relative changes in these 2 components influence primary production in the Southern Ocean.

\section{METHODS}

A 1-dimensional model was used to compute the depth-dependent variation in primary production as a function of the spectral distribution of incoming solar radiation $(280$ to $700 \mathrm{~nm}$ ). Included in the model were separate components for calculating the flux of atmospheric radiation, in-water bio-optics, and primary production. The model calculated the rate of gross primary production ( $\mathrm{mg} \mathrm{C} \mathrm{m} \mathrm{m}^{-3} \mathrm{~d}^{-1}$ ) at $1 \mathrm{~m}$ vertical resolution on an hourly basis as a function of diurnal changes in spectral irradiance. Production was integrated over depth (the euphotic depth, $0.1 \%$ of surface light, $\sim 75 \mathrm{~m}$ ) and time $(24 \mathrm{~h})$ to determine daily production on an areal basis (GPP, mg $\mathrm{C} \mathrm{m}^{-2} \mathrm{~d}^{-1}$ ). Model input included day of the year, latitude, seawater temperature $\left({ }^{\circ} \mathrm{C}\right)$, stratospheric $\left[\mathrm{O}_{3}\right](\mathrm{DU})$, and initial phytoplankton concentration ( $\mathrm{mg} \mathrm{C} \mathrm{m}^{-3}$ ). The effects of changes in UV and PUR were determined independently by setting a flag that controls whether UV inhibition was calculated or not. If inhibition was not calculated, changes in production resulting from diminished $\mathrm{O}_{3}$ were due to variation in PUR only.

\section{THE MODEL}

The clear sky atmospheric radiation model of Gregg \& Carder (1990) was extended to include radiation between 280 and $700 \mathrm{~nm}$. This model was chosen because it contains a simple, yet accurate, parameterization for marine aerosols, is of high spectral resolution $(1 \mathrm{~nm})$, calculates direct and diffuse radiation components, and includes an improved formulation for absorption by $\mathrm{O}_{3}$. The primary weakness of this model is that it does not include multiple scattering, a process that increases the effective radiation path-length. Because short wavelengths in the UV range are partic- 
Fig. 1. Spectral distributions for (A) extraterrestrial radiation, $(B)$ water vapor absorption, (C) ozone absorption, (D) attenuation of solar radiation by clear seawater, (E) typical algal absorption, and $(F)$ biological weighting function for the inhibition of phytoplankton photosynthesis by ultraviolet radiation. The extraterrestrial radiation spectrum is from Neckel \& Labs (1984) and VanHoosier et al. (1988); water vapor absorption from Gregg \& Carder (1990); ozone absorption from Molina \& Molina (1986); algal absorption from D. Robinson (pers comm.); and the biological weighting function from Cullen et al. (1992)
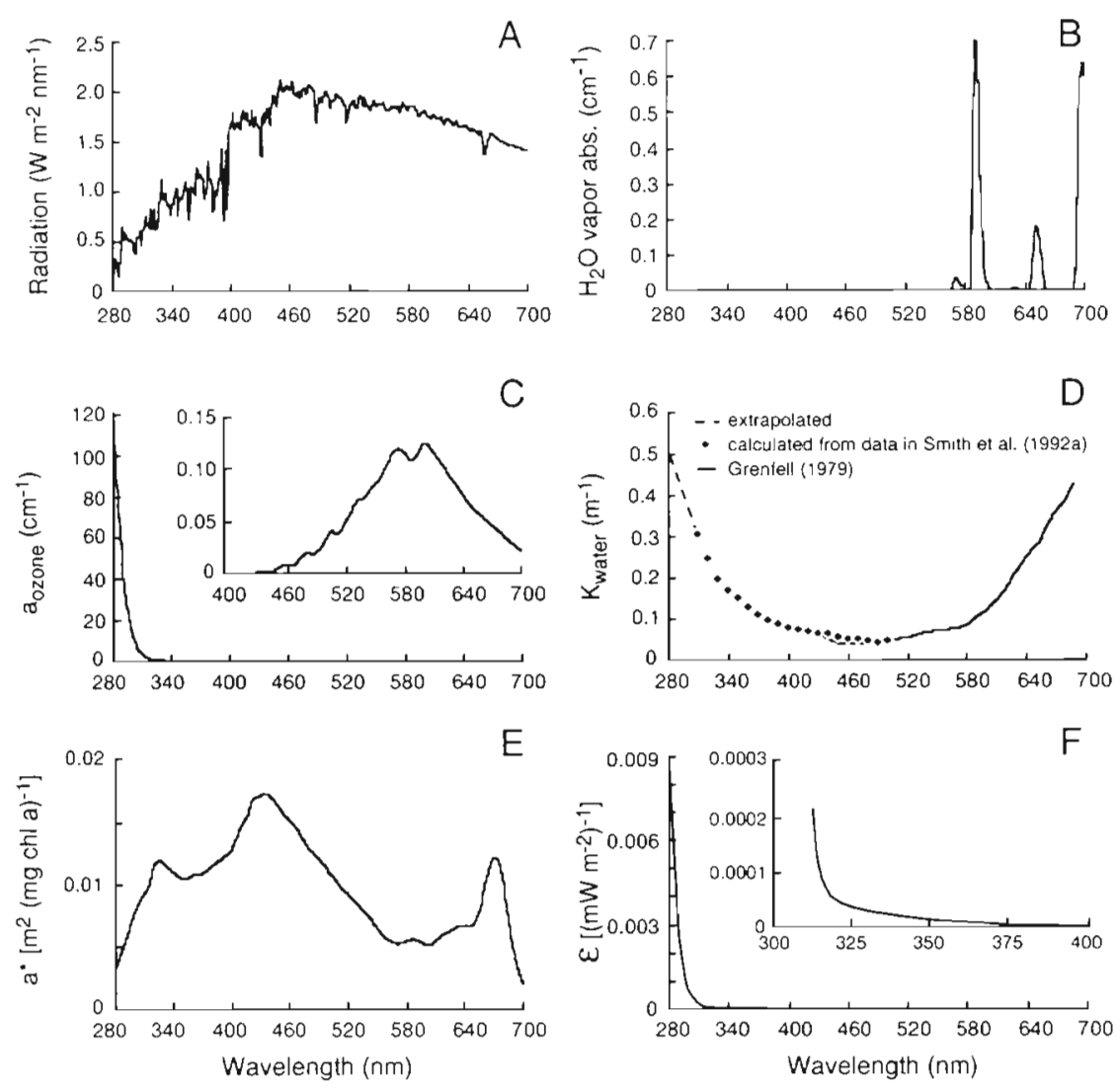

ularly sensitive to multiple scattering effects, this model may overestimate UV transmission by approximately $10 \%$, depending on zenith angle (Smith et al. 1992b). Thus, the increase in UVB transmission due to $\mathrm{O}_{3}$ depletion would be somewhat less than has been predicted here. In the Gregg \& Carder (1990) model, extraterrestrial radiation (Fig. 1A) is reduced by absorption by water vapor (Fig. 1B), ozone (Fig. 1C), and oxygen, by Rayleigh scattering, and by marine aerosol absorption and scattering.

The downwelling spectral irradiance just penetrating the ocean surface, $E_{\mathrm{d}}(\lambda, 0-, t)$, at time $t$ is calculated as

$$
E_{d}(\lambda, 0-, t)=\left(1-\alpha_{d}\right) E_{\mathrm{dd}}(\lambda, 0, t)+\left(1-\alpha_{1}\right) E_{\mathrm{d}}(\lambda, 0, t)
$$

where $E_{\mathrm{dd}}$ and $E_{\mathrm{di}}$ are the direct and indirect radiation components, $\alpha_{d}$ and $\alpha_{i}$ are the specular reflectance for direct and indirect radiation, and 0 - and 0 refer to the positions just below and just above the ocean surface, respectively. Fresnel's Law is used to calculate $\alpha_{d}$

$$
\alpha_{d}=0.5\left[\frac{\sin ^{2}\left(\theta-\theta_{w}\right)}{\sin ^{2}\left(\theta+\theta_{w}\right)}+\frac{\tan ^{2}\left(\theta-\theta_{w}\right)}{\tan ^{2}\left(\theta+\theta_{w}\right)}\right]
$$

where $\theta$ is the solar zenith angle and $\theta_{\mathrm{w}}=\sin ^{-1}[0.75$ $\sin (\theta)$ ]. For diffuse radiation, $\alpha_{i}=0.066$ (Burt 1954).
Spectral light penetration through the water column was computed using the Beer-Lambert law

$$
E_{\mathrm{d}}(\lambda, z, t)=E_{\mathrm{d}}(\lambda, z-\Delta z, t) \exp [-K(\lambda, z) \Delta z]
$$

where $K(\lambda, z)$ is the diffuse attenuation coefficient $\left(\mathrm{m}^{-1}\right)$ at depth $z . K(\lambda, z)$ was calculated as

$$
K(\lambda, z)=K_{\mathrm{w}}(\lambda)+K_{\mathrm{p}}(\lambda, z)
$$

where $K_{\mathrm{w}}(\lambda)$ and $K_{\mathrm{p}}(\lambda, z)$ are the extinction coefficients for clear ocean water (Fig. 1D) and particulates, respectively. Although the presence of gelbstoffe and detritus can alter the optical properties of the water column appreciably, they are generally found at low concentrations in Southern Ocean waters (Mitchell 1991, Mitchell \& Holm-Hansen 1991) and have been ignored.

$K_{\mathrm{p}}(\lambda, z)$ was computed as

$$
K_{\mathrm{p}}(\lambda, z)=\frac{b_{\mathrm{bc}}(\lambda, z)+a_{c}^{*}(\lambda) C(z)}{\mu}
$$

where $b_{\mathrm{bc}}(\lambda, z)$ is the backscatter $\left(\mathrm{m}^{-1}\right)$ by microalgae computed according to the procedure described in Sathyendranath et al. (1989), $a^{*}{ }_{C}(\lambda)\left(\mathrm{m}^{2} \mathrm{mg} \mathrm{chl} \mathrm{a}^{-1}\right)$ is 
the pigment-specific absorption coefficient for microalgae (Fig. 1E), $C(z)$ is the pigment concentration (mg chl $a \mathrm{~m}^{-3}$ ), and $\mu$ (dimensionless) is the mean cosine for downwelling radiation. The coefficient $\mu$ is equal to $\cos \left(\theta_{w}\right)$ for direct light and to 0.83 and for diffuse (Sathyendranath et al. 1989).

Gross microalgal production ( $\mathrm{mg} \mathrm{C} \mathrm{m}^{-3} \mathrm{~h}^{-1}$ ) at depth $z$ and time $t$ was calculated as

$$
\frac{\partial P}{\partial t}(z, t)=G(z, t) P(z, t)
$$

where $G$ is the microalgal growth rate $\left(h^{-1}\right)$ and $P$ is the standing crop $\left(\mathrm{mg} \mathrm{C} \mathrm{C}^{-3}\right)$. Assuming that macronutrients in the Southern Ocean are in abundance (modeling trace metal limitation is beyond the scope of this study), $G$ is a function of the temperature-dependent upper limit to growth, $G_{\max }\left(\mathrm{d}^{-1}\right)$, and a light-limitation term, $\rho$ (dimensionless) such that

$$
G(z, t)=\rho(z, t) G_{\max }(z) .
$$

$G_{\max }(z)$ and $\rho(z)$ were calculated according to the equations:

$$
\begin{gathered}
G_{\max }(z)=G_{0} \exp [r T(z)] \\
\rho(z, t)=\left[1-\exp \left(-\frac{\operatorname{PUR}(z, t)}{I_{k}^{\prime}(z)} \xi\right)\right]\left(\frac{1}{1+E_{\text {inh }}^{*}(z, t)}\right)
\end{gathered}
$$

where $G_{0}\left(\mathrm{~d}^{-1}\right)$ is the microalgal growth rate at $0^{\circ} \mathrm{C}$ (0.8511) and $r\left({ }^{\circ} \mathrm{C}^{-1}\right)$ is a rate constant $(0.0633)$ that determines the sensitivity of $G_{\max }$ to temperature, $T$ $\left({ }^{\circ} \mathrm{C}\right)($ Eppley 1972). Eq. (9) is the phytoplankton lightlimitation term and consists of 2 parts. The first part, enclosed in brackets, describes light limitation as a function of both PUR $(z, t)\left(\mu\right.$ Ein $\left.\mathrm{m}^{-2} \mathrm{~s}^{-1}\right)$ and the spectral photoadaptation parameter, $I_{k}^{\prime}(z)\left(\mu\right.$ Ein $\left.\mathrm{m}^{-2} \mathrm{~s}^{-1}\right)$ (Arrigo \& Sullivan 1994). Phytoplankton growth is effectively light-saturated when PUR $=3 I_{k}{ }^{\prime}$. The coefficient $\zeta$ adjusts for the differences in the $C$ : chl a ratio expected at the light levels of $\operatorname{PUR}(z, t)$ and of $I_{k}^{\prime}(z)$ according to Eq. (14) below, thus allowing photosynthetic measurements to be used to calculate growth. The second part of Eq. (9) is dimensionless, varying from 0 to 1 , and calculates UV inhibition as a function of the distribution of spectral irradiance from 280 to $400 \mathrm{~nm}$ and a corresponding biological weighting function according to Eq. (16) below (Cullen et al. 1992)

The inclusion of PUR in Eq. (9) allows algal growth to vary as a function of the spectral irradiance and the absorption characteristics of microalgae. PUR was calculated following Morel (1978):

$$
\operatorname{PUR}(z, t)=\int_{\lambda=A 00}^{700} E_{\mathrm{d}}(\lambda, z, t) \frac{a^{*}{ }_{c}(\lambda)}{a^{*}{ }_{c \max }} \mathrm{d} \lambda
$$

where $a_{c_{\max }}$ is the maximum value attained by $a_{c}^{*}(\lambda)$. Although photosynthetic absorption occurs at wavelengths below $400 \mathrm{~nm}$, Eq. (10) has been employed so that PUR is distinct from UVA. PUR $(z, t)$ is used to calculate PUR', a measure of the average amount of usable radiation available during the photoperiod $(F)$ between the sea surface and the base of the euphotic zone $\left(D_{E}\right)$, according to the equation

$$
\mathrm{PUR} \cdot=\frac{\int_{t=12-F / 2}^{12+F / 2} \int_{z=0}^{D_{\mathrm{E}}} \operatorname{PUR}(z, t) \mathrm{d} z \mathrm{~d} t}{\int_{t=12-F / 2}^{12+F / 2} \int_{z=0}^{D_{\mathrm{E}}} \mathrm{d} z \mathrm{~d} t}
$$

$I_{k}{ }^{\prime}(z)$ in Eq. (9) varies as a function of PUR - according to the equations (Arrigo \& Sullivan 1994)

$$
\begin{aligned}
& I_{k}^{\prime}(z)=\frac{I_{k}{ }^{\prime} \max }{1+2 \exp \left[-B \mathrm{PUR}^{*}\right]} \\
& B=\exp \left[1.089-2.12 \log \left(I_{k_{\text {max }}^{\prime}}^{\prime}\right)\right]
\end{aligned}
$$

where $I_{k \text { miax }}$ is the maximum observed value for $I_{k}{ }^{\prime}$. Lizotte \& Arrigo (1994) compiled spectral irradiance data and corresponding values of $I_{k}$ ' for phytoplankton collected over a wide range of times, depths, and locations in the Southern Ocean and determined that $I_{k}{ }^{\prime} \max$ $=74.4 \mu \mathrm{Ein} \mathrm{m}^{-2} \mathrm{~s}^{-1}$. Eqs. (12) \& (13) scale $I_{k}^{\prime}(z)$ with depth to simulate photoadaptation such that $I_{k}{ }^{\prime}(z)=$ $\operatorname{PUR}^{\circ}(z)$ at intermediate depths and asymptotically approaches $I_{k}{ }^{\prime}$ max and $I_{k}{ }^{\prime} \min \left[\approx 0.33 I_{k}{ }^{\prime}\right.$ max as defined in Eq. (12)] toward the surface and base of the euphotic zone, respectively.

The coefficient $\zeta$ in Eq. (9) was calculated as

$$
\zeta=\frac{\mathrm{C}: \mathrm{chl} a \text { at } \mathrm{PAR}=\operatorname{PAR}(z)}{\mathrm{C}: \mathrm{chl} a \text { at } \mathrm{PAR}=I_{k}(z)} .
$$

An analysis of data for Skeletonema costatum given in Sakshaug et al. (1989) showed that at high growth rates (when nutrients were in abundance) $\mathrm{C}$ :chl a was a function of daily integrated radiation (Ein $\mathrm{m}^{-2} \mathrm{~d}^{-1}$ ) computed as the product of the photoperiod, $F$, and PAR. The equation used here to describe this relationship is

$$
\text { C:chl } a=33.125+9.77 F \text { PAR. }
$$

Cullen et al. (1992) computed $E_{\text {inh }}^{\text {( }}(z, t)$ from the wavelength-dependent biological efficiency for damage to photosynthesis by UV, $\varepsilon(\lambda)\left[\left(\mu \text { Ein } \mathrm{m}^{-2} \mathrm{~s}^{-1}\right)^{1}\right]$, and the flux of UV radiation

$$
E^{\cdot} \cdot \ln (z, t)=\int_{\lambda=280}^{400} \varepsilon(\lambda) E_{\mathrm{d}}(\lambda, z, t) \mathrm{d} \lambda
$$


where $\varepsilon(\lambda)$ (Fig. 1F) was determined for the diatom Phaeodactylum sp. It should be noted that the shape of $\varepsilon(\lambda)$ was similar for a variety of photosynthetic taxa from diverse habitats, including the dinoflagellate Prorocentrum micans (Cullen et al. 1992), the vascular plant Rumex patientia (Rundel 1983), and Antarctic sea ice microalgae (Mitchell 1990, Lubin et al. 1992)

\section{EXPERIMENTAL DESIGN}

Algal growth was simulated for a single cloud-free day assuming ice-free conditions and initial profiles of chl a $\left(0.5 \mathrm{mg} \mathrm{m}^{-3}\right)$ and water temperature $\left(1^{\circ} \mathrm{C}\right)$ that were uniform with depth. This standardized each simulation and eliminated interpretation problems that develop when the model is run for a longer time and calculated state variables (i.e. phytoplankton standing crop) diverge. Most results are presented in terms of GPP.

Expt A (168 simulations) assessed the temporal and latitudinal effects of a $50 \%$ reduction in column $\mathrm{O}_{3}$ (from 344 to 172 DU) on phytoplankton production. Simulations covered latitudes between 50 and $75^{\circ} \mathrm{S}$ (approximately the southernmost point of the Southern Ocean) from August 8 to December 26. The impact of $\mathrm{O}_{3}$-induced changes in PUR and UV radiation on algal production were separated and analyzed as a function of time and latitude.

Expt B (378 simulations) determined the effect of observed $\left[\mathrm{O}_{3}\right]$ on primary production along a northsouth transect (from 50 to $75^{\circ} \mathrm{S}$ ) at $45^{\circ} \mathrm{W}$ longitude between August 28 and December 6 for the years 1980 ,
1985, and 1990. Total column $\left[\mathrm{O}_{3}\right\}$ data were obtained from the total ozone mapping spectrometer (TOMS) aboard the Nimbus 7 satellite. An additional 105 simulations were performed for $64^{\circ} \mathrm{S}, 72^{\circ} \mathrm{W}$ in the Bellingshausen Sea, the location of the Icecolors 1990 cruise that studied, among other things, primary production beneath an $\mathrm{O}_{3}$ hole (Smith et al. 1992a). Estimates of GPP computed using observed $\left[\mathrm{O}_{3}\right]$ were normalized to simulations which used as input the 'normal' $\left[\mathrm{O}_{3}\right]$ of 344 DU (referred to hereafter as baseline simulations). Both the inhibitory effects of UV and enhancement effects of PUR were included.

\section{RESULTS}

\section{Effects of temporal and latitudinal variation in $\left[\mathrm{O}_{3}\right]$ on GPP}

GPP for baseline simulations increased temporally at all latitudes tested (Fig. 2). The temporal change was particularly great at $75^{\circ} \mathrm{S}$, where GPP increased from near zero to $>160 \mathrm{mg} \mathrm{C} \mathrm{m}^{-2} \mathrm{~d}^{-1}$ between August 28 and December 16 (Fig. 2D). The dynamic range in GPP at $50^{\circ} \mathrm{S}$ was much less, increasing from 46 to $98 \mathrm{mg} \mathrm{C}$ $\mathrm{m}^{-2} \mathrm{~d}^{-1}$ between August 8 and December 16 (Fig. 2A), due primarily to a more seasonally uniform photoperiod at higher latitudes. Removing the effects of UV inhibition resulted in markedly higher rates of GPP over baseline simulations. The magnitude of this difference is a measure of UV inhibition under normal $\mathrm{O}_{3}$ conditions and will be referred to as $\triangle G P P_{n} . \Delta G P P P_{n}$ was frequently large and dependent upon latitude and
Fig. 2. Results for Expt A showing the temporal changes in GPP at $\left[\mathrm{O}_{3}\right]=$ 344 DU when UV inhibition was calculated (baseline simulation) and when UV inhibition was ignored, for the latitudes of (A) $50^{\circ} \mathrm{S}$, (B) $60^{\circ} \mathrm{S}$, (C) $70^{\circ} \mathrm{S}$, and (D) $75^{\circ} \mathrm{S}$. Each point represents a separate simulation. The difference between the 2 curves is a measure of UV inhibition under normal conditions

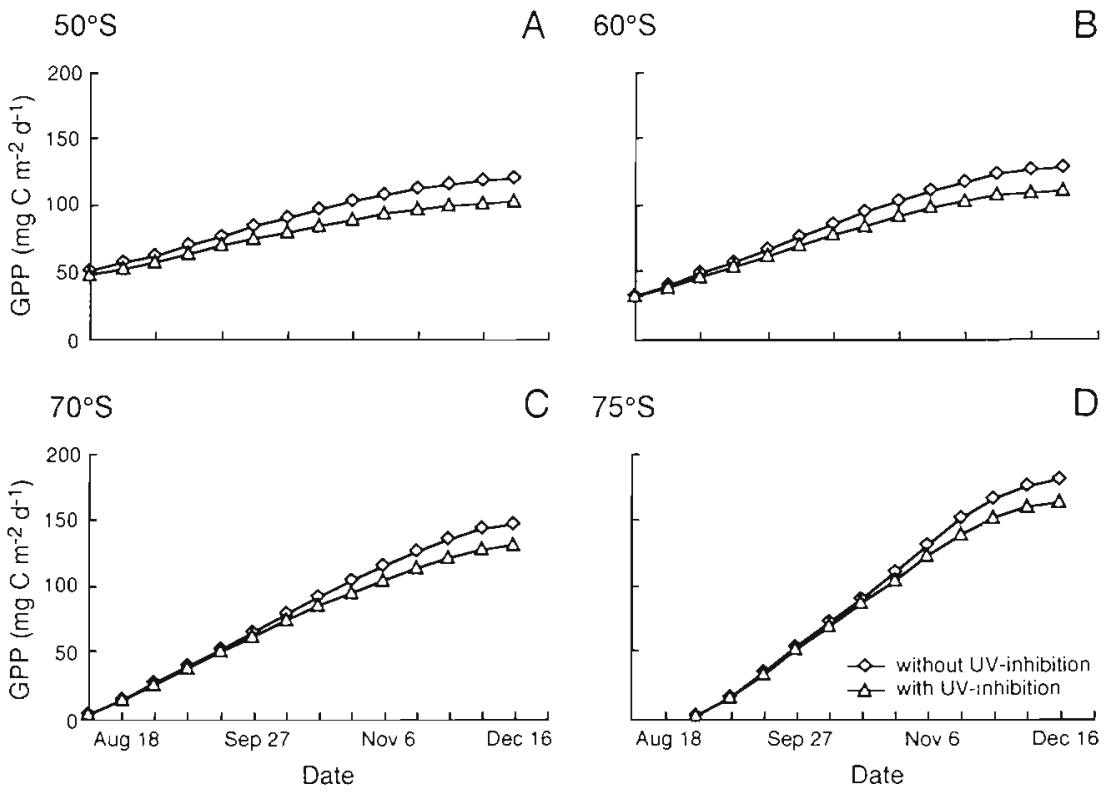


Table 1. Percent inhibition of gross primary production at noon at the sea surface. Values do not include the enhancement effects of changes in PUR. Values are percent. Numbers in parentheses denote percent of total (UVA + UVB) inhibition

\begin{tabular}{|ccccc|}
\hline & $\begin{array}{c}\text { August } 28 \\
75^{\circ} \mathrm{S}\end{array}$ & $\begin{array}{c}\text { August 28 } \\
50^{\circ} \mathrm{S}\end{array}$ & $\begin{array}{c}\text { December 16 } \\
75^{\circ} \mathrm{S}\end{array}$ & $\begin{array}{c}\text { December 16 } \\
50^{\circ} \mathrm{S}\end{array}$ \\
\hline$\left[\mathrm{O}_{3}\right]=344 \mathrm{DU}$ & & & & \\
$\mathrm{UVA}$ & $0.18(99.5)$ & $23.0(92.3)$ & $28.5(73.4)$ & $40.2(70.0)$ \\
$\mathrm{UVB}$ & $0.00(0.50)$ & $1.90(7.70)$ & $10.3(26.6)$ & $17.2(30.0)$ \\
UVA+UVB & 0.18 & 24.9 & 38.8 & 57.4 \\
& & & & \\
{$\left[\mathrm{O}_{3}\right]=172 \mathrm{DU}$} & & & & $40.2(64.5)$ \\
UVA & $0.18(96.8)$ & $23.0(83.7)$ & $28.5(66.6)$ & $22.1(35.5)$ \\
UVB & $0.01(3.20)$ & $4.4(16.3)$ & $14.3(33.4)$ & 22.3 \\
UVA+UVB & 0.19 & 27.4 & 42.8 & \\
\hline
\end{tabular}

on December 16 (Fig. 3E) at $50^{\circ} \mathrm{S}$. Most of this inhibition ( 70 to $92 \%$ ) was due to UVA.

The change in GPP resulting from a reduction in stratospheric $\left[\mathrm{O}_{3}\right]$ (termed $\triangle \mathrm{GPP}_{\mathrm{O}_{3}}$ ) from the normal level of $344 \mathrm{DU}$ to $172 \mathrm{DU}$ varied depending on latitude and date. Early in the spring, $\triangle G P P_{O_{3}}$ was generally positive, meaning that a decrease in $\mathrm{O}_{3}$ elicited an increase in GPP, attaining values as high as $+9 \%$ (Fig. 4). This enhancement of GPP was due to the increased transmission of photosynthetic radiation at low $\left[\mathrm{O}_{3}\right]$ which was most pronounced at higher latitudes. For example, a $50 \%$ reduction in $\left[\mathrm{O}_{3}\right]$ resulted in a $10.1 \%$ increase in PAR at the

date, being greatest (17\%) on December 16 at $50^{\circ} \mathrm{S}$ (Fig. 2A) when solar zenith angles were smallest, and least (no inhibition) on August 28 at $75^{\circ} \mathrm{S}$ (Fig. 2D) when the sun was closer to the horizon. In addition, $\triangle G P P_{n}$ varied greatly with depth, being maximal near the surface where rates of primary production at noon were reduced by $25 \%$ on August 28 (Table 1) and $57 \%$ surface and a $7.2 \%$ increase at $25 \mathrm{~m}$ on September 7 at $75^{\circ} \mathrm{S}$ (Fig. 5A). At these large solar zenith angles, GPP was relatively low near the ocean surface and declined exponentially with depth in all simulations (Fig. 3B). The degree of UV inhibition early in spring was slight and dominated by UVA (Fig. 3C), which accounted for 82 to $99 \%$ of total UV inhibition in surface waters
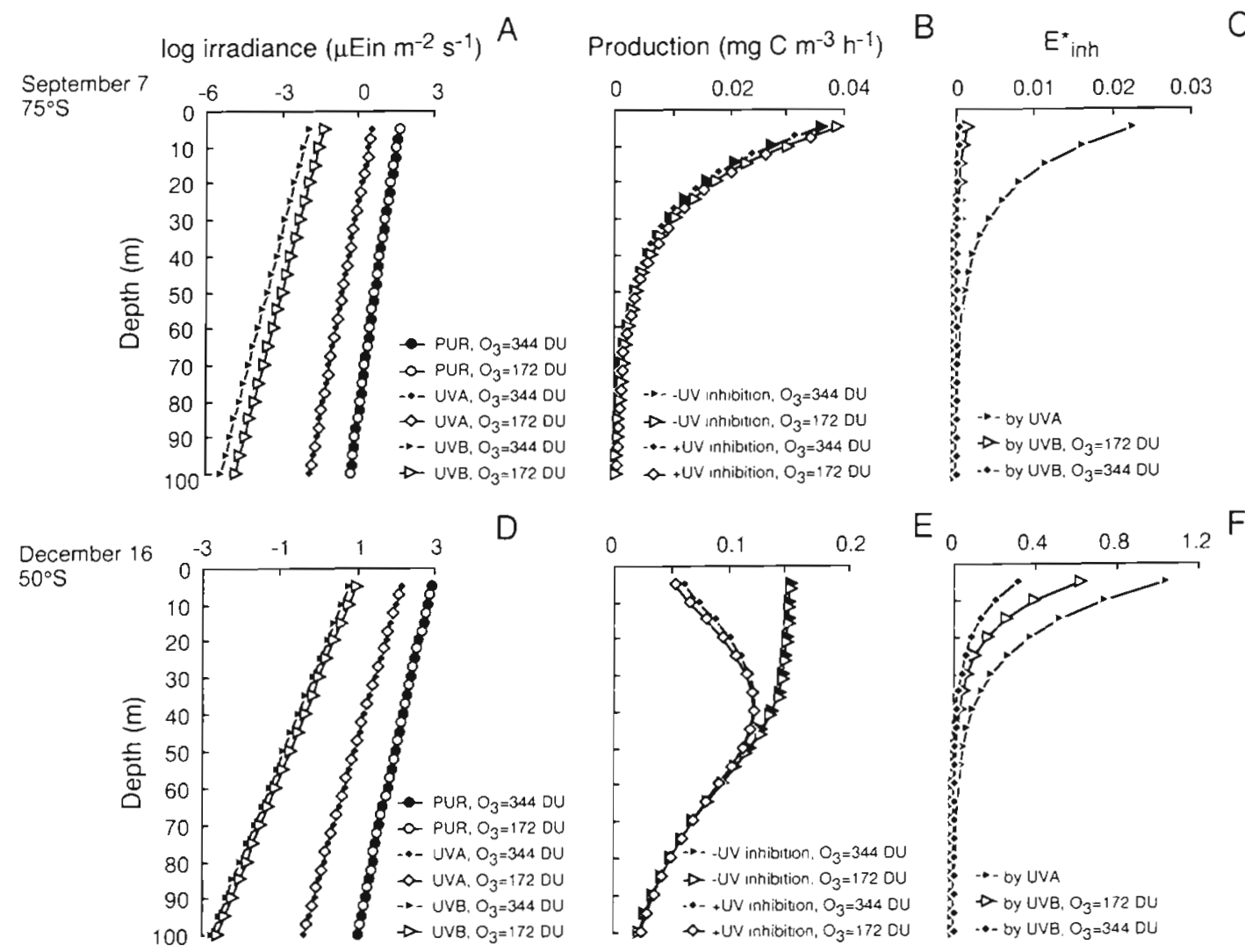

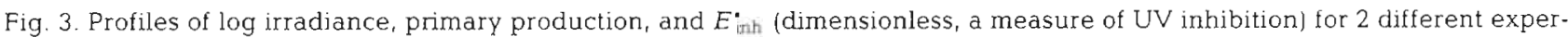
imental treatments. These treatments represent the approximate upper and lower bounds of incident radiation (magnitude, photoperiod, zenith angles) in the Southern Ocean and were chosen to illustrate the wide range of values predicted by the model 


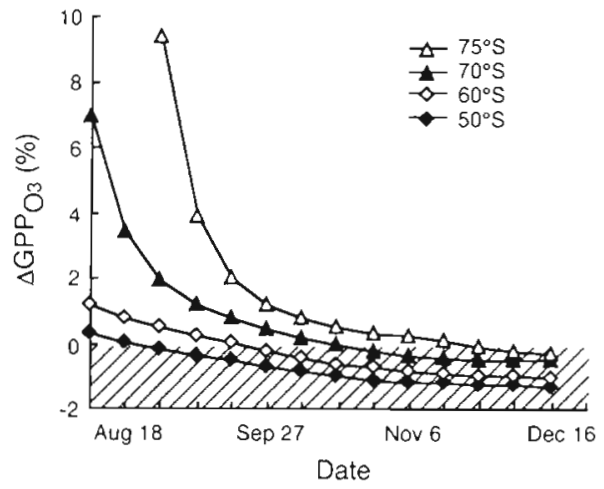

Fig. 4. The change in GPP resulting from a decrease in $\left[\mathrm{O}_{3}\right]$ from 344 to $172 \mathrm{DU}\left(\triangle \mathrm{GPP} \mathrm{O}_{3}\right)$ as a function of latitude. The shaded region denotes where $\triangle \mathrm{GPP}_{\mathrm{O}_{3}}<0$ (i.e. net UVB inhibition). At $\triangle \mathrm{GPP}_{\mathrm{O}_{3}}=0, \mathrm{UV}$ inhibition exactly balances PUR-induced enhancement of GPP. Each point represents a separate simulation

(Table 1). However, the predicted PUR-induced enhancement in GPP at low $\left[\mathrm{O}_{3}\right]$ due to increased transmission of PUR more than offset the slight inhibition of GPP due to increased UVB. The transmission of UVA is insensitive to changes in $\left[\mathrm{O}_{3}\right]$ so its effect did not change with experimental treatment.

As the season progressed, PUR-induced enhancement of GPP diminished considerably, due to the reduced sensitivity of photosynthetic radiation to $\left[\mathrm{O}_{3}\right]$ at smaller zenith angles. For instance, on December 16 at $50^{\circ} \mathrm{S}$ when zenith angles were relatively low, a $50 \%$ reduction in $\left[\mathrm{O}_{3}\right]$ resulted in only a $1.1 \%$ increase in PAR at the sea surface and $0.7 \%$ increase at $25 \mathrm{~m}$ (Fig. 5B). This increase is an order of magnitude lower than predicted for noon on September 7 at $75^{\circ} \mathrm{S}$. At all latitudes, the offsetting effects of UV inhibition and PUR enhancement of GPP eventually reached a balance (i.e. where $\triangle \mathrm{GPP}_{\mathrm{O}_{3}}=0$ ), although the precise timing varied greatly (Fig. 4). Increasing latitude from 50 to $75^{\circ} \mathrm{S}$ resulted in a $100 \mathrm{~d}$ delay in the net reduction of GPP to below baseline levels. By December 16, a $50 \%$ reduction in $\left[\mathrm{O}_{3}\right]$ resulted in a slightly negative $\triangle \mathrm{GPP}_{\mathrm{O}_{3}}$ at all latitudes, which ranged from -0.5 to $-1.0 \%$.

\section{Effects of observed $\mathrm{O}_{3}$ depletion on GPP}

In 1980, 1985, and 1990, stratospheric $\left[\mathrm{O}_{3}\right]$ decreased with increasing latitude along $45^{\circ} \mathrm{W}$ (Fig. 6A, C, E), i.e. $\mathrm{O}_{3}$ depletion was greatest at higher latitudes. Mean $\left[\mathrm{O}_{3}\right]$ between August 28 and December 6 and for the region between 50 and $75^{\circ} \mathrm{S}$ decreased markedly, from $330 \mathrm{DU}$ in 1980 to $283 \mathrm{DU}$ in 1985 and $269 \mathrm{DU}$ in 1990. Minimum $\left[\mathrm{O}_{3}\right]$ was generally observed between October 7 and 27, regardless of year or latitude. In 1980 , the minimum $\left[\mathrm{O}_{3}\right]$ was $\sim 220 \mathrm{DU}$ (Fig. $6 \mathrm{~A}$ ); this
September $7,75^{\circ} \mathrm{S}$

A

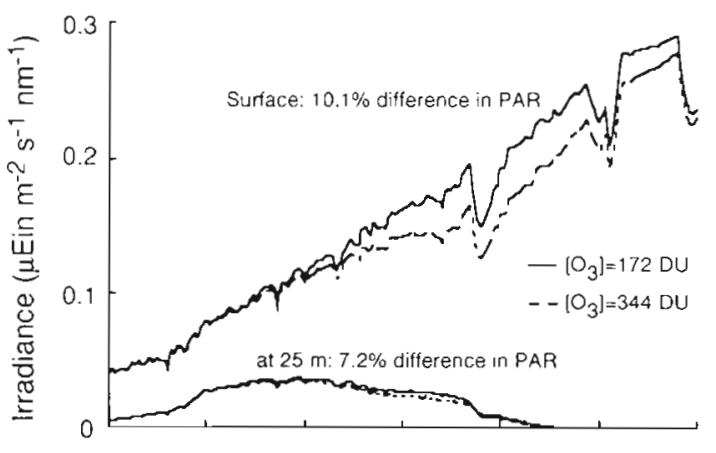

December $16,50^{\circ} \mathrm{S}$

B

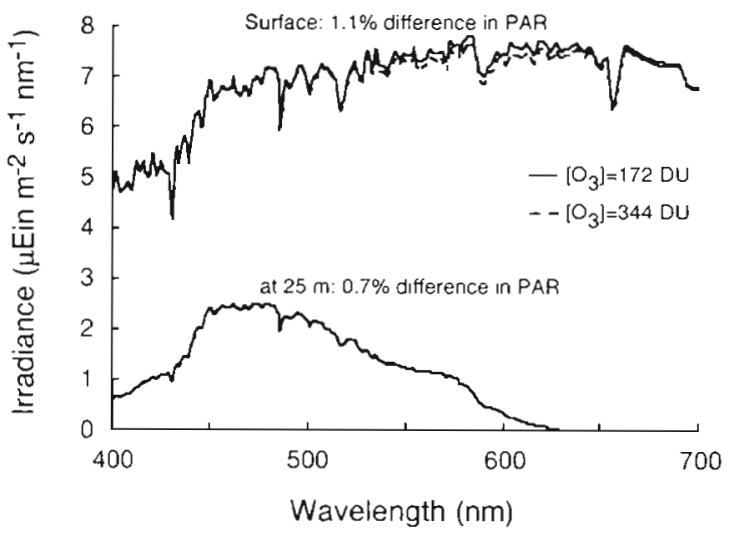

Fig. 5. Changes in spectral irradiance at the ocean surface and at a depth of $25 \mathrm{~m}$ for $\left[\mathrm{O}_{3}\right]$ of $172 \mathrm{DU}$ and $344 \mathrm{DU}$ for (A) September 7 and (B) Deember 16 at $50^{\circ} \mathrm{S}$

value decreased to $160 \mathrm{DU}$ in 1985 (Fig. 6C) and to 150 DU by 1990 (Fig. 6E). Concentrations of $\mathrm{O}_{3}$ generally rebounded to near normal values by late November, regardless of latitude or year.

The most striking result of the simulations for Expt $B$ was the relatively large positive values for $\triangle \mathrm{GPP}_{\mathrm{O}_{3}}$ at latitudes south of $65^{\circ} \mathrm{S}$ due to increased PUR transmission in early spring The temporal patterns of this enhancement (Fig. 6B, D, F) were similar to the pattern observed in Expt A (Fig. 4). In both cases, the degree of enhancement was greatest on or about August 28 at high latitudes when solar zenith angles were small. When observed $\left[\mathrm{O}_{3}\right]$ was used as model input, as was done in Expt B, maximum enhancement increased from $1.8 \%$ in 1980 (Fig. 6B) to $3.8 \%$ in 1990 (Fig. 6F). These enhancements were considerably smaller than the maximum of $+9 \%$ predicted in Expt $\mathrm{A}$. This is because observed $\left[\mathrm{O}_{3}\right]$ generally remained higher than the 172 DU assumed in Expt A (except between September 27 and November 6 in 1985 and 1990). North of $65^{\circ} \mathrm{S}$, substantial enhancement was not observed in either experiment. 

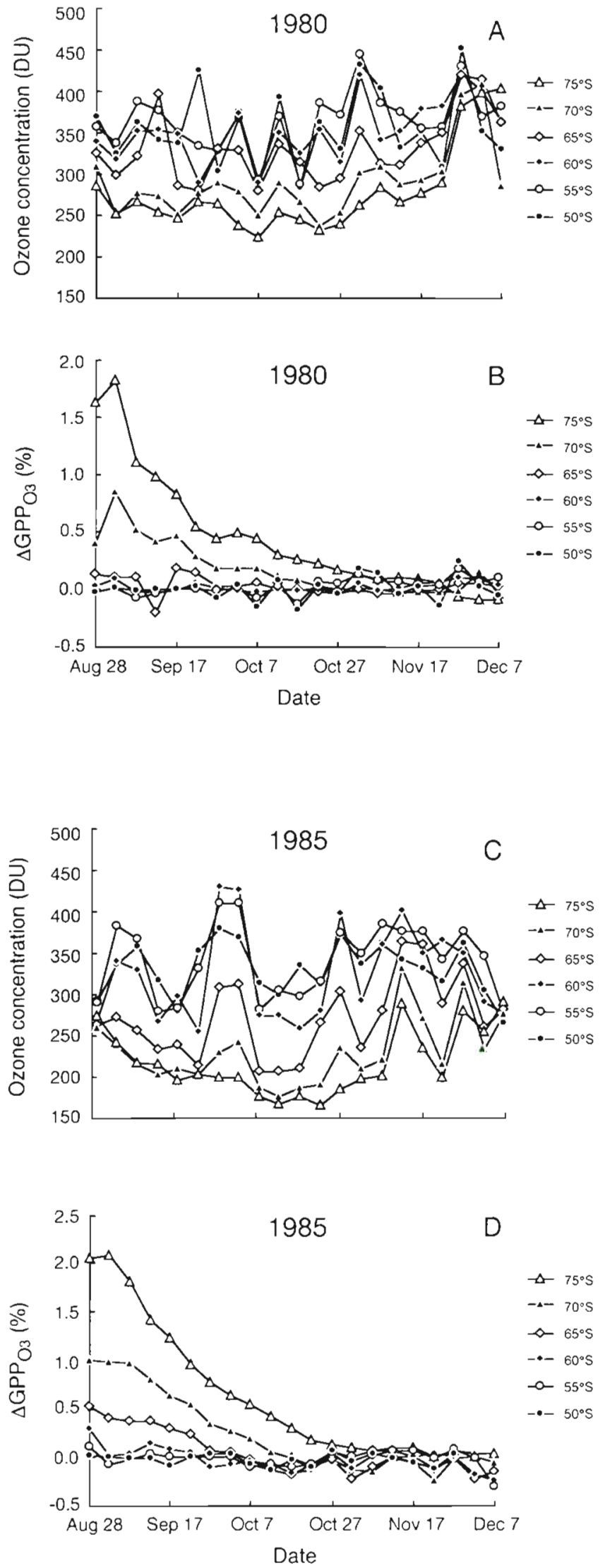
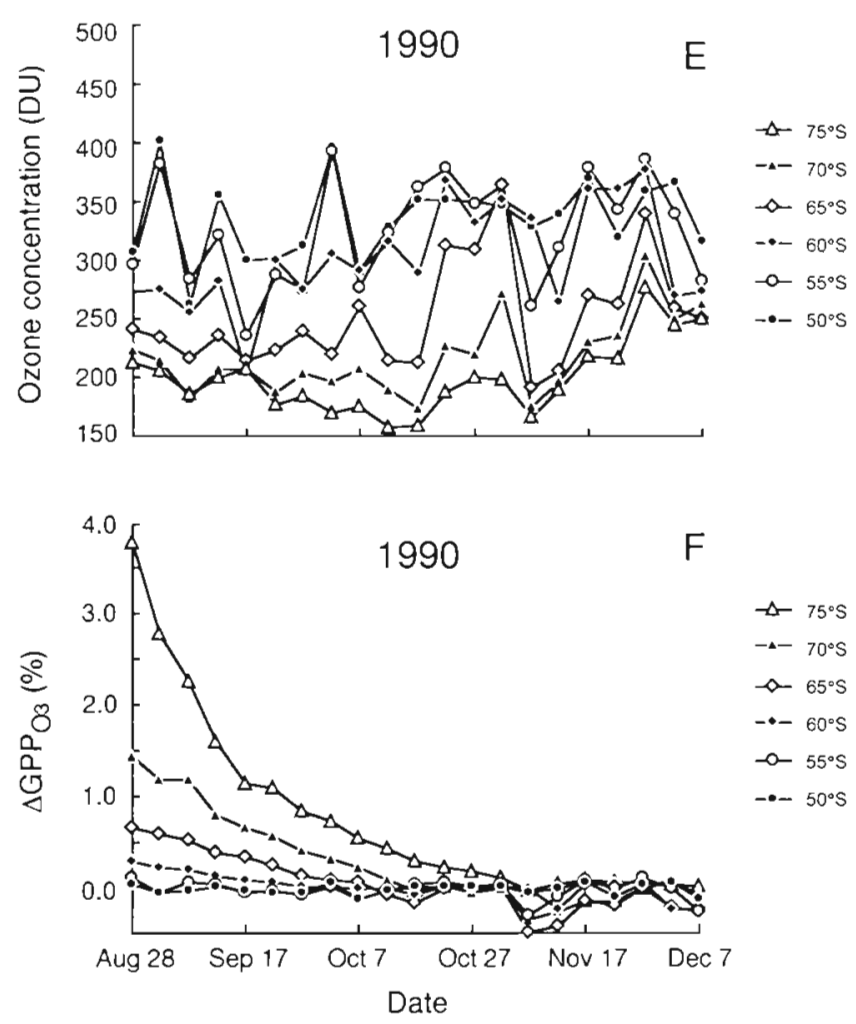

Fig. 6. (A) Variation in total column $\mathrm{O}_{3}$ in 1980 as a function of time and latitude along $45^{\circ} \mathrm{W}$ and $(\mathrm{B})$ the percent change in gross primary production $\left(\triangle \mathrm{GPP} \mathrm{P}_{3}\right)$ resulting from use of observed $\left[\mathrm{O}_{3} \mid\right.$ as model input instead of the 'normal' value of 344 DU. (C) and (D) are same as above but for 1985. (E) and (F) are same as above but for 1990 . Note that early in the season at high latitudes GPP increases when $\left[\mathrm{O}_{3}\right]$ is low due to increased transmission of PUR. TOMS data obtained from National Space Science Data Center, NASA/Goddard Space

Flight Center, Code 633.4, Greenbelt, MD 20771, USA

$\triangle \mathrm{GPP}_{\mathrm{O}_{3}}$ was surprisingly small compared to $\triangle \mathrm{GPP}_{n}$, regardless of $\left[\mathrm{O}_{3}\right]$, latitude, or date, indicating that UV inhibition of GPP under normal $\mathrm{O}_{3}$ conditions is much larger than the increase in UV inhibition induced by reduced $\left[\mathrm{O}_{3}\right]$. Maximum reduction in phytoplankton production did not necessarily coincide with minimum $\left[\mathrm{O}_{3}\right]$, as might be expected, but reflected a balance between changes in $\mathrm{O}_{3}$, PUR, and the increased flux of UV characteristic of lower latitudes. For example, in 1980, GPP was reduced at most by an additional $-0.25 \%$ (on September 12 at $65^{\circ} \mathrm{S}$ ) over levels predicted at normal $\left[\mathrm{O}_{3}\right]$ (Fig. 6B). However, rather than coinciding with a diminished $\left[\mathrm{O}_{3}\right]$, this low production rate was attributable to a reduction in PUR, a consequence of an unusually high springtime $\left[\mathrm{O}_{3}\right]$ of 400 DU. True UV inhibition of GPP below the level in baseline simulations was predicted only at the lowest lati- 
tudes ( 50 to $55^{\circ} \mathrm{S}$ ) in 1980 , and $\triangle \mathrm{GPP}_{\mathrm{O}_{3}}$ never exceeded $-0.23 \%$. In $1985, \triangle \mathrm{GPP}_{\mathrm{O}_{3}}$ was only slightly higher, reaching a maximum level of $-0.30 \%$ at $55^{\circ} \mathrm{S}$ on December 6 when $\left[\mathrm{O}_{3}\right]$ declined to $260 \mathrm{DU}$ (Fig. 6D). Similarly, $\triangle \mathrm{GPP}_{\mathrm{O}_{3}}$ was greater in 1990 (Fig. $6 \mathrm{~F}$ ), but not substantially so; maximum inhibition was $-0.5 \%$.

To further illustrate the balance between inhibition by UV and enhancement by PUR for GPP, $\left[\mathrm{O}_{3}\right]$ measured during the $6 \mathrm{wk}$ Icecolors cruise to the Bellingshausen Sea (Smith et al. 1992a) were used as input to the model. $\left[\mathrm{O}_{3}\right]$ varied from $165 \mathrm{DU}$ to $365 \mathrm{DU}$ over the study site (Fig. 7A), reflecting the dynamic nature of the $\mathrm{O}_{3}$ hole as it rotated within the Antarctic vortex. The model results for the Icecolors $\left[\mathrm{O}_{3}\right]$ scenario were compared to baseline simulations where $\left[\mathrm{O}_{3}\right]=$ 344 DU. The effect of increased UVB was most extreme near the sea surface on November 11, when inhibition of primary production was predicted to reach $-13 \%$. Inhibition declined rapidly to a depth of $\sim 30 \mathrm{~m}$ where the simulated effects of UV were $<-1 \%$.

For the euphotic water column as a whole, maximum $\triangle \mathrm{GPP}_{\mathrm{O}_{3}}(-1.5 \%)$ occurred on November 11 (Fig. $7 \mathrm{~B}$ ), coinciding with the minimum observed $\left[\mathrm{O}_{3}\right]$. In general, however, inhibition of GPP at low $\left[\mathrm{O}_{3}\right]$ due to increased UVB transmission was predicted to be almost completely offset by the enhancement of GPP due to the increase in PUR. Both effects were small, however, with $\triangle \mathrm{GPP}_{\mathrm{O}_{3}}$ generally $<-0.5 \%$.

\section{DISCUSSION}

The primary conclusion to be drawn from these results is that the incremental increase in UV inhibition of GPP elicited by a realistic decrease in $\left[\mathrm{O}_{3}\right]$ is invariably small, rarely exceeding $1 \%$, and always far less than the level of UV inhibition occurring at normal $\left[\mathrm{O}_{3}\right]$. In this respect, the results presented here support the conclusions of Holm-Hansen et al. (1993) who suggested that increased UV transmission resulting from reduced $\left[\mathrm{O}_{3}\right]$ has only a marginal impact on phytoplankton in the Southern Ocean. The agreement between our 2 studies is remarkable considering the vast differences in the approaches employed. However, the estimate of $1 \%$ reported here is somewhat lower than the UV inhibition computed by HolmHansen et al. (1993) $(3.8 \%)$ and far less than the 6 to $12 \%$ reported by Smith et al. (1992a) under reduced $\mathrm{O}_{3}$ conditions. There are a number of reasons why results of numerical simulations may differ quantitatively from field observations. Most reflect the fact that relevant parameters can be controlled explicitly in simulations; this is almost never the case in the field where conditions are often beyond the control of the investigator.
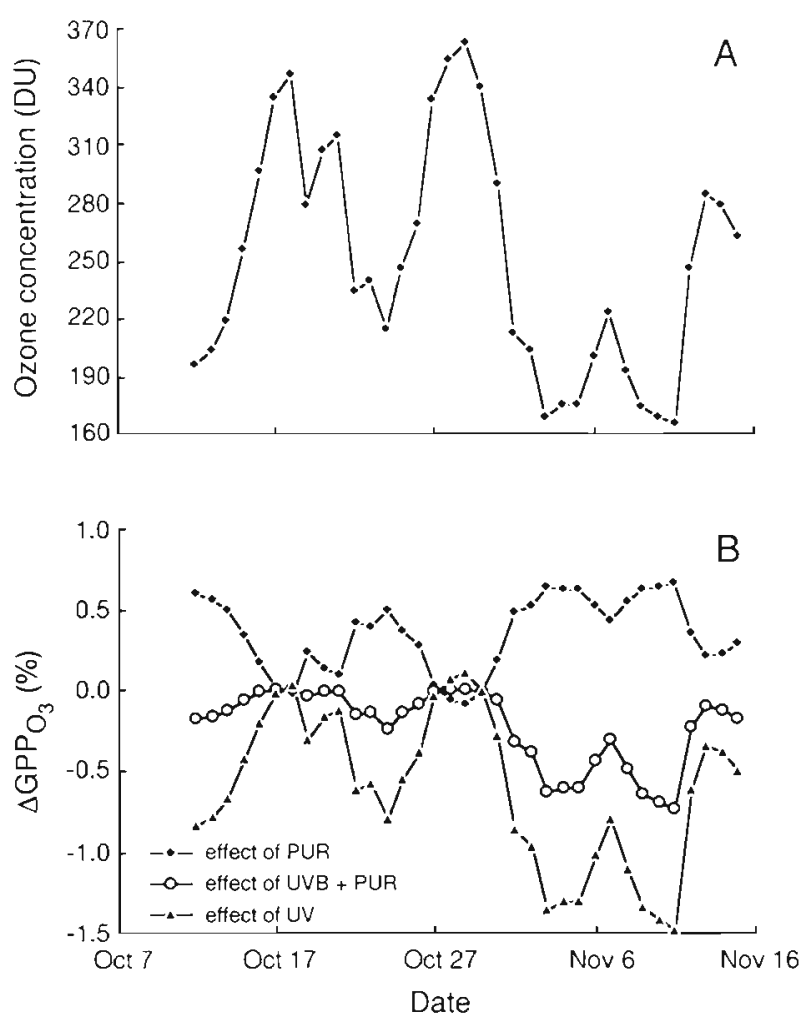

Fig. 7. (A) Total column $\mathrm{O}_{3}$ measured during the Icecolors cruise (Smith et al. 1992a) and (B) the computed change in production resulting from the use of measured $\left[\mathrm{O}_{3}\right]$ rather than 344 DU as model input. The effects of PUR, UV, and UV + PUR have been separated

First, it is difficult, if not impossible, to measure the enhancement of GPP by increased PUR at low $\left[\mathrm{O}_{3}\right]$ in most field studies. Holm-Hansen et al. (1993) estimated UVB inhibition to be $3.8 \%$ when $\left[\mathrm{O}_{3}\right]$ was reduced from 350 to $150 \mathrm{DU}$ (for comparison, UV inhibition is only $2.9 \%$ when $\left[\mathrm{O}_{3}\right]$ is reduced from 344 to $172 \mathrm{DU}$, as was done here) using the UV action spectrum of Helbling et al. (1992) and measured changes in atmospheric UV radiation at $161 \mathrm{DU}$ and $330 \mathrm{DU}$. If the enhancement effects of decreased $\left[\mathrm{O}_{3}\right]$ on PUR are included, estimates of UV inhibition would be reduced by as much as $1 \%$ (Fig. $7 \mathrm{~B}$ ), to levels closer to those obtained in simulations. This enhancement effect at low $\left[\mathrm{O}_{3}\right]$ is particularly important at latitudes higher than $70^{\circ} \mathrm{S}$, including the highly productive coastal regions of the Weddell and Ross Seas, where the model suggests that a balance exists between PUR enhancement and UV inhibition of phytoplankton growth. It must also be remembered that the effect of reduced $\mathrm{O}_{3}$ on the amount and spectral distribution UV radiation is strongly dependent upon solar zenith angle (i.e. at larger zenith angles, more UVB is attenuated for a given $\left[\mathrm{O}_{3}\right]$ than at small solar zenith angles). Therefore, estimates of UVB inhibition made using a solar 
UV radiation spectrum measured at a specific time and place (Holm-Hansen et al. 1993) must be made with caution. The model does not suffer from this problem; unique atmospheric radiation spectra are obtained for each time and location.

Second, simulated rates of UV inhibition at low $\left[\mathrm{O}_{3}\right]$ may be higher than the in situ values reported previously due to the necessity for 6 to $12 \mathrm{~h}$ incubation times in field studies, which often are centered at midday (Smith et al. 1992a, Holm-Hansen et al. 1993). Integrating UV effects for the entire photoperiod (up to $24 \mathrm{~h}$ ) and over the whole euphotic zone, thus incorporating those depths and times when the flux of UVB is small, typically reduces estimates of UV inhibition by $50 \%$ (depending on date and latitude). Depth corrections of UV inhibition can be made easily (HolmHansen et al. 1993) but temporal corrections are much more problematic. More seriously, it has been found that the use of polyethylene incubation vessels in some field programs are subject to UV-induced 'toxicity' and may reduce primary productivity to $50 \%$ of values reported in quartz vessels when UV radiation was present (Holm-Hansen \& Helbling 1993). Problems associated with UV-induced 'toxicity' from polyethylene incubation vessels may explain the high estimates of UV inhibition ( 6 to $12 \%$ ) and the unusual pattern of increased UV inhibition with depth reported for phytoplankton collected from the Bellingshausen Sea (Smith et al. 1992a), a pattern in sharp contrast to results of other studies (i.e. Harris 1978, Lorenzen 1979, Cullen et al. 1992, Holm-Hansen et al. 1993).

Third, species-specific variation in tolerance to increased levels of UVB (Karentz et al. 1991, Smith et al. 1992a) could be important. Phaeocystis pouchetii, a dominant species during the Icecolors cruise (Smith et al. 1992a), and indeed in most polar oceans, may be particularly sensitive to UV (Smith et al. 1992a), but could not be explicitly accommodated in the model due to lack of appropriate biological weighting functions for this species. Moreover, because the model is based on the assumption that the response of 2 Antarctic phytoplankton species, Phaeodactylum sp. and Prorocentrum micans, to a 45 min exposure of UV can be extrapolated to the entire photoperiod, processes of photorepair that require longer exposure have not been accounted for. If such mechanisms are important, the model will have overestimated the magnitude of UVB inhibition of GPP. In contrast, it has been suggested that the ratio of UVB:UVA or UVB:PAR may act as a cue to initiate repair of UV photodamage (Smith et al. 1992a). Photorepair mechanisms that depend on these radiation ratios may be more adversely affected by extreme variation in $\left[\mathrm{O}_{3}\right]$ than is allowed by the present model. It is possible, however, that these 2 influences on photorepair will counteract each other.
Finally, due to a paucity of optical data below $310 \mathrm{~nm}$, values for diffuse attenuation of pure seawater were extrapolated from $K_{\mathrm{vv}}(310)$ to $K_{\mathrm{vv}}(330)$ to obtain values between $K_{\mathrm{wv}}(280)$ and $K_{\mathrm{w}}(310)$. Although much care was taken, this extrapolation could have resulted in attenuation coefficients which were too high in this range, removing too much UVB, and yielding estimates of UVB inhibition that were too low. This is unlikely to be the case, however, for 2 reasons. First, sufficient UVB radiation was transmitted to depths $>20 \mathrm{~m}$ in all simulations to result in a net inhibition of phytoplankton growth at those depths. This is consistent with in situ profiles which showed that UVB is inhibiting to photosynthesis down to depths of at least $20 \mathrm{~m}$ (Holm-Hansen et al. 1993). In fact, the model predicted slight UVB inhibition to approximately $50 \mathrm{~m}$ deeper than had been observed in the field. Because some UV radiation is certainly transmitted to those depths (UV will never be completely attenuated, it can just be reduced to undetectable limits), this supports the idea that there is a threshold UV dose below which inhibition will not occur (Holm-Hansen et al. 1993). At the present time, the model does not support the use of such a threshold. Second, sensitivity analyses revealed that a linear decrease in $K_{\mathrm{w}}$ of $25 \%$ at $280 \mathrm{~nm}$ (from 0.5 to $0.4 \mathrm{~m}^{-1}$ ) to $0 \%$ at $330 \mathrm{~nm}$ resulted in only a $1 \%$ increase in production at the sea surface and $\ll 1 \%$ increase in GPP. Thus, relatively large errors in $K_{\mathrm{w}}$ between 280 and $310 \mathrm{~nm}$ translate to only small errors in GPP and cannot explain the low estimates of increased UVB inhibition at low $\left[\mathrm{O}_{3}\right]$.

The results presented here further show that UVA dominates total UV inhibition regardless of $\left[\mathrm{O}_{3}\right]$ and solar zenith angle, being responsible for 65 to $>99 \%$ of total UV inhibition. These conclusions are consistent with observations made by Helbling et al. (1992) who showed that $>50 \%$ of total UV inhibition in surface waters was caused by UVA. The estimate by Helbling et al. (1992) would be expected to be lower than the $>65 \%$ reported here because their incubations were carried out on the deck of a ship where UVB radiation is relatively more abundant, and therefore, will have a greater inhibitory effect. Holm-Hansen et al. (1993) also reported that inhibition by 320 to $360 \mathrm{~nm}$ light was responsible for $>55 \%$ of total UV inhibition, in line with our estimate of $>65 \%$ for 320 to $400 \mathrm{~nm}$ light. Because the transmission of UVA is insensitive to $\left[\mathrm{O}_{3}\right]_{\text {, }}$ these results imply that changes in stratospheric $\left[\mathrm{O}_{3}\right]$ are unlikely to have more than a slight impact on total primary production by phytoplankton in the Southern Ocean

Even if the potential impact of increased UVB transmission were greater than predicted here, the physical structure of the Southern Ocean would tend to minimize its effect. First, the high southern latitudes 
where depletion of $\mathrm{O}_{3}$ is most severe (south of $65^{\circ} \mathrm{S}$ ) coincide with the region where PUR-induced enhancement of GPP is relatively large, offsetting some of the deleterious effects of increased UVB transmission. For example, while $\left[\mathrm{O}_{3}\right]$ dropped to nearly $150 \mathrm{DU}$ on October 12,1990, at $75^{\circ} \mathrm{S}, \mathrm{GPP}$ was stil] enhanced slightly relative to baseline simulations. At latitudes north of $65^{\circ} \mathrm{S}$, where zenith angles are reduced and radiation path-lengths are shorter, $\left[\mathrm{O}_{3}\right]$ was rarely ever depleted and few dates exhibited substantial UV inhibition of GPP.

Second, although in theory phytoplankton blooms in the MIZ may be susceptible to damage by UVB, the timing of the $\mathrm{O}_{3}$ hole development greatly restricts the potential impact of increased UVB on phytoplankton production (Helbling et al. 1994). The depletion of $\mathrm{O}_{3}$ is greatest south of $60^{\circ} \mathrm{S}$ and at the time (i.e. OctoberNovember) when sea ice extent in the Southern Ocean is at its peak (Comiso et al. 1993). From early September to late November, sea ice extends from the Antarctic continent northward to between 60 and $65^{\circ} \mathrm{S}$ where $\mathrm{O}_{3}$ depletion is relatively mild (Fig. 8). Therefore, open water regions will not be exposed to the high UVB doses experienced by ice-covered regions at higher latitudes. In addition, the rapid degradation of sea ice, which precedes the phytoplankton blooms in the MIZ (Nelson \& Smith 1986, Smith \& Nelson 1986), takes place between November and March (Comiso et al. 1993), after the $\mathrm{O}_{3}$ hole has diminished. Most MIZ phytoplankton blooms have been observed much later (see Nelson \& Smith 1986 for review). Because sea ice and its associated snow cover attenuates UV radiation very effectively, little damaging UVB reaches the water column (Perovich 1993, but see Trodahl \& Buckley 1989,1990$)$. It is likely that the algal populations most susceptible to increased UVB transmission will be those associated with sea ice, although information about the susceptibility of individual ice algal species to enhanced UV is lacking.

Most importantly, the results presented here should not be interpreted to suggest that reduced $\left[\mathrm{O}_{3}\right]$ will be good for the Southern Ocean ecosystem by providing for higher rates of primary production. It must be remembered that PUR-induced enhancement of GPP at low $\left[\mathrm{O}_{3}\right]$ will be most pronounced at those times when baseline GPP is lowest, i.e. at high latitudes and early in the season. For example, in Expt $\mathrm{A}$, baseline GPP was $<6 \mathrm{mg} \mathrm{C} \mathrm{m}^{-2} \mathrm{~d}^{-1}$ early in the season when the enhancement due to PUR was maximal (Figs. 2D \& 4). In contrast, baseline GPP was $>98 \mathrm{mg} \mathrm{C} \mathrm{m}^{-2} \mathrm{~d}^{-1}$ when UV inhibition was at its peak. This trend of high enhancement/low production was also true for Expt $B$ where actual $\mathrm{O}_{3}$ values were used. The net effect of PUR enhancement of GPP over a wide range of latitudes is likely to be small, and will not completely
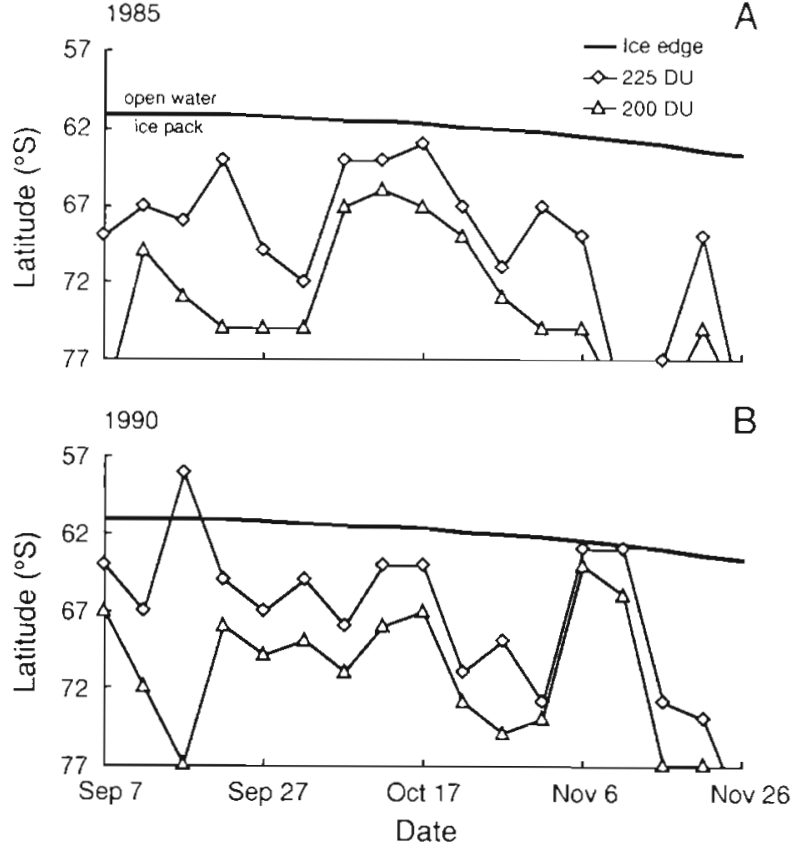

Fig. 8. Time series showing positions of the ice edge and the $200 \mathrm{DU}$ and $225 \mathrm{DU} \mathrm{O}_{3}$ isopleths for (A) 1985 and (B) 1990 along $45^{\circ} \mathrm{W}$ (Weddell Sea). Note that the lowest $\left[\mathrm{O}_{3}\right]$ are located over ice-covered regions for the duration of the $\mathrm{O}_{3}$ hole

offset the inhibitory effects of increased UVB at lower latitudes, particularly later in the spring and summer.

At present, fears that phytoplankton production could fall catastrophically in the face of diminished $\left[\mathrm{O}_{3}\right]$, affecting the whole Southern Ocean ecosystem (El-Sayed 1988), appear exaggerated. Nevertheless, if the temporal and spatial coverage of the $\mathrm{O}_{3}$ hole expands, if sea ice dynamics change, or if $\left[\mathrm{O}_{3}\right]$ is reduced further, the impact on phytoplankton populations may be more severe than the minimal amount predicted here. Clear evidence already exists to suggest that stratospheric $\mathrm{O}_{3}$ is becoming increasingly depleted over the Antarctic vortex, where concentrations as low as 88 DU were reported on October 6, 1993 (Walker 1993). Additionally, in recent years the $\mathrm{O}_{3}$ hole has reached as far north as the southern tip of South America. Whether phytoplankton in the Southern Ocean ecosystem will be capable of adapting to these and future changes in their environment is not yet known.

Acknowledgements. The author thanks W. Gregg for providing the code and input parameters for the atmospheric radiative transfer model. I am also grateful to $\mathrm{M}$. Lizotte for use of his Pl data for Southern Ocean phytoplankton, and to $O$. Holm-Hansen for a fruitful discussion concerning Southern Ocean phytoplankton and for his timely handling of this manuscript. Special thanks to Greg Mitchell and 2 anonymous ref- 
erees for their helpful comments during the review process This work was supported by a U.S. Department of Energy Global Change Distinguished Postdoctoral Fellowship to K.R.A. and administered by Oak Ridge Institute for Science and Education.

\section{LITERATURE CITED}

Anderson, J. G., Toohey, D. H., Brune, W. H. (1991). Free radicals within the Antarctic vortex: the role of CFCs in Antarctic ozone loss. Science 251: $39-46$

Arrigo, K. R., Sullivan, C. W. (1994). A high resolution biooptical model of microalgal growth: tests using sea ice algal community time series data. Limnol. Oceanogr. 39: 609-631

Burt, W. V. (1954). Albedo over wind-roughened water. J. Meteorol. 11: 383-289

Comiso, J. C., McClain, C. R., Sullivan, C. W., Ryan, J P., Leonard, C. L. (1993). Coastal zone color scanner pigment concentrations in the Southern Ocean and relationships to geophysical surface features. J geophys. Res. 98 2419-2451

Cullen, J. C., Neale, P. J., Lesser, M. P. (1992). Biological weighting function for the inhibition of phytoplankton photosynthesis by ultraviolet radiation. Science 258 : $646-650$

El-Sayed, S. Z. (1988). Fragile life under the ozone hole. Nat. Hist. $97(10): 72-80$

Eppley, R. W. (1972). Temperature and phytoplankton growth in the sea. Fish. Bull. U.S. 70: 1063-1085

Gregg, W W., Carder, K. L. (1990). A simple spectral solar irradiance model for cloudless maritime atmospheres. Limnol. Oceanogr. 35: 1657-1675

Harris, G. P. (1978). Photosynthesis, productivity and growth: the physiological ecology of phytoplankton. Arch. Hydrobiol. Beih. Ergebn. Limnol. 10: 10-171

Helbling, E. W., Villafane, V., Ferrario, M., Holm-Hansen, O. (1992). Impact of natural ultraviolet radiation on rates of photosynthesis and on specific marine phytoplankton species. Mar. Ecol. Prog. Ser. 80: 89-100

Helbling, E. W., Villafane, V., Holm-Hansen, O. (1994). Effects of ultraviolet radiation on Antarctic marine photosynthesis with particular attention to the influence of mixing. In: Weiler, S., Penhale, P. (eds.) Ultraviolet radiation and biological research in Antarctica. Antarct. Res. Ser. 62: $207-227$

Holm-Hansen, O., Helbling, E. W. (1993). Polyethylene bags and solar ultraviolet radiation. Science 259: 534

Holm-Hansen, O., Helbling, E. W., Lubin, D. (1993). Ultraviolet radiation in Antarctica: inhibition of primary production. Photochem. Photobiol. 58: 567-570

Karentz, D., Cleaver, J. E., Mitchell, D. L. (1991). Cell survival characteristics and molecular responses of Antarctic phytoplankton to ultraviolet-B radiation. J. Phycol. 27 326-341

Lizotte, M. P.. Arrigo, K. R. (1994). Parameterization of a spectral model of primary production in the Southern Ocean Eos 75(3): 217

Lorenzen, C. J. (1979). Ultraviolet radiation and phytoplankton photosynthesis. Limnol. Oceanogr. 24: 1117-1120

Lubin, D., Mitchell, B. G., Frederick, J E., Alberts, A. D.,

This article was presented by O. Holm-Hansen (Senior

Editonal Advisor), La Jolla, California, USA
Booth, C. R., Lucas, T., Neuschuler, D. (1992). A contribution toward understanding the biospherical significance of Antarctic ozone depletion. J. geophys. Res. 97: 7817-7828

Mitchell. B. G. (1990). Action spectra of ultraviolet photoinhibition of Antarctic phytoplankton and a model of spectral diffuse attenuation coefficients, In: Mitchell, B. G., Sobolev, I., Holm-Hansen, O. (eds.) Response of marine phytoplankton to natural variations in UVB flux. Chemical Manufacturers Association, Washington, DC, p. 1-10

Mitchell, B. G. (1991). Predictive bio-optical relationships for polar oceans and marginal ice zones. J. mar. Sys. 3 : 91-105

Mitchell, B. G., Holm-Hansen, O. (1991). Bio-optical properties of Antarctic peninsula waters: differentiation from temperate ocean models. Deep Sea Res. 38: 1009-1028

Molina, L. T., Molina, M. J. (1986). Absolute absorption cross sections of ozone in the $185-350 \mathrm{~nm}$ wavelength range J. geophys. Res. 91: 14501-14509

Morel, A. (1978). Available, usable, and stored radiant energy in relation to marine photosynthesis. Deep Sea Res. 25 $673-688$

Neckel, H., Labs, D. (1984). The solar radiation between 3300 and $12500 \AA$. Solar Phys. 90: 205-258

Nelson, D. M., Smith, W. O. (1986). Phytoplankton bloom dynamics of the western Ross Sea ice edge II. Mesoscale cycling of nitrogen and silicon. Deep Sea Res. 33 $1389-1412$

Perovich, D. K. (1993). Ultraviolet light transmission through Antàrctic sea ice. Eos 73(43): 291

Rundel, R. D. (1983). Action spectra and estimation of biolog ically effective UV radiation. Physiol. Plant. 58: 360-366

Sakshaug, E., Andresen, K., Kiefer, D. (1989). A steady-state description of growth and light absorption in the marine planktonic diatom Skeletonema costatum. Limnol Oceanogr. 34: 198-205

Sathyendranath, S., Platt, T., Caverhill, C. M., Warnock, R. E., Lewis, M. R. (1989). Remote sensing of oceanic primary production: computations using a spectral model. Deep Sea Res. 36: 431-453

Smith, R. C., Prezelin, B. B., Baker, K. S., Bidigare, R. R. Boucher, N. P., Cooley, T., Karenz. D., MacIntyre, S., Matlick, H. A., Menzies, D., Ondrusek, M., Wan, Z., Waters, K. J (1992a). Ozone depletion: ultraviolet radiation and phytoplankton biology in Antarctic waters. Science 255: 952-959

Smith, R. C., Wan, Z., Baker, K. S. (1992b). Ozone depletion in Antarctica: modeling its effect on solar UV irradiance under clear-sky conditions. J. geophys. Res. 97: 7383-7397

Smith, W. O. Jr, Nelson, D. M. (1986). The importance of iceedge blooms in the Southern Ocean. BioSci. 26: 251-257

Trodahl, H. J., Buckley, R. G. (1989). Ultraviolet levels under sea 1ce during the Antarctic spring. Science 245: 194-195

Trodahl. H. J., Buckley, R. G. (1990). Enhanced ultraviolet transmission of Antarctic sea ice during the Austral spring. Geophys. Res. Lett. 17: 2177-2179

VanHoosier, M. E., Bartoe, J. D., Brueckner, G. E., Prnnz, D. K. (1988). Absolute solar spectral irradiance $120 \mathrm{~nm}-400 \mathrm{~nm}$ (results from the Solar Ultraviolet Spectral Irradiance Monitor-SUSIM-Experiment on board Spacelab 2). Astrophys. Lett. Commun. 27. 163-168

Walker, G. (1993). Weather contributes to record ozone loss. Nature 365: 683

Manuscript first received: December 6, 1993

Revised version accepted: June 23, 1994 